\title{
Flood modelling and impact of debris flow in the Madarsoo River, Iran
}

\author{
S. Tjerry ${ }^{1}$, O. Z. Jessen ${ }^{2}$, K. Morishita ${ }^{3}$ \& H. G. Enggrob ${ }^{2}$ \\ ${ }^{1}$ DHI Inc, Portland, Oregon, USA \\ ${ }^{2}$ DHI Water \& Environment, Hørsholm, Denmark \\ ${ }^{3}$ CTII, Tokyo, Japan
}

\begin{abstract}
Madarsoo River with a catchment area of $2360 \mathrm{~km}^{2}$ originates in the Alborz Mountains, runs through the national Golestan Forest and into Golestan reservoir. Three major flashfloods have taken place during the past five years, and oddly enough all three flashfloods took place in the dry season (mid-August), with the largest recent flashflood (10 August 2001) killing about 250 people, mostly in the Golestan Forest. Debris flow occurs along part of the Madarsoo where the tributaries have high slopes and intense rainfall. The objectives of the present study are to produce flood maps for the area and to assess the hydraulic impact of debris flow. The work has been carried out as part of "The Study on Flood and Debris Flow in the Caspian Coastal Area Focusing on the Flood-Hit Region in Golestan Province" financed by Japan International Cooperation Agency (JICA).

Keywords: flashfloods, hydrological modelling, hydraulic modelling, morphological modelling, GIS, debris flow, flood mapping, disaster management.
\end{abstract}

\section{Introduction}

Three models were constructed for the Madarsoo River. A hydrological model consisting of coupled MIKE SHE and MIKE 11 models was used at basin scale for determining the distributed inflows to the river system. A MIKE 11 hydraulic model covering the reach from Dasht village to Golestan Dam was used for hydraulic modelling and flood mapping. Finally a local morphological model with inclusion of debris flow was used for quantifying the hydraulic impact of 
the debris flow. Debris yields were determined from empirical methods for historically debris prone tributaries.

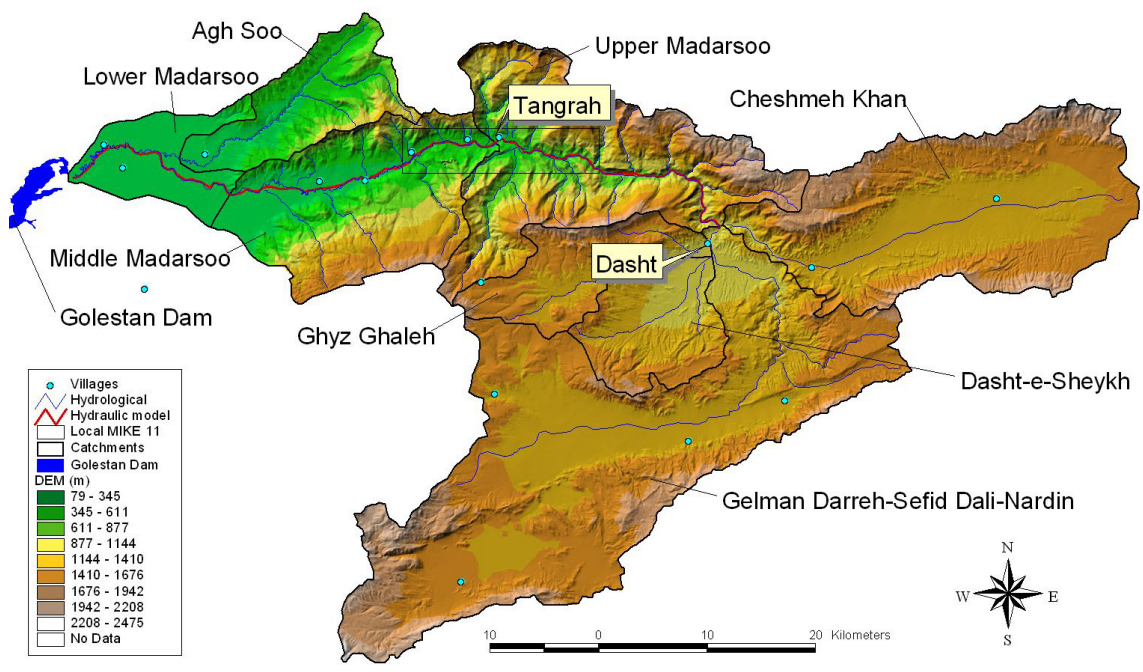

Figure 1: Madarsoo basin with DEM, network and eight catchments.

The upstream end of the hydraulic model (Dasht) is indicated in fig. 1, which is also the upstream entrance to Golestan Forest where Madarsoo conveys all the water from the upstream catchments. The water then flows down Madarsoo River through Golestan Forest, after which it enters into a wider valley downstream of Tangrah and finally enters into a wide terrace floodplain before emptying into Golestan reservoir. Golestan Forest is by far the most dangerous area during the floods due to the very narrow valley with large flood depths and velocities. The road through Golestan Forest is part of an international corridor linking Tehran and Marshad, and most fatalities during the large (return period 55 years) 2001 August 10 flood were campers in Golestan Forest, many travelling between Tehran and Marshad.

\section{Hydrological modelling}

A basin scale hydrological model was constructed with the objective of determining the dynamic discharge variation in the river system. Doing so required description of the inflow to the river system and a detailed description of the hydrodynamic processes in the rivers, and hence the hydrological model was developed with focus on the fast runoff to the river system, including the fractioning of the water flow into surface flow, interflow and sub-surface flow. The project focuses on flood issues and as such the sub-surface flow or baseflow is considered to be of less importance while the surface and interflow is critical for a proper description of the study area, see e.g. El-Nasr et al. [1]. 
During periods with heavy rainfall the interflow and surface flow will be the main contributors to the discharge in the river system. Consequently a detailed description of these two processes was required, while the base flow, for flood purposes, could be described with less detail. For the land based part the focus was on a detailed description of the surface related processes, and the effects of different land use descriptions and slope designs. For the description of the processes in the river the focus was on a detailed description of the hydrodynamic processes in the river, and impacts from structures (weirs, bridges or dams) were considered. A conceptual flow model includes detention storage in the vegetation cover, infiltration and actual evapotranspiration, overland flow, infiltration to the saturated zone, interflow contribution to rivers, baseflow contribution to the rivers and a full hydrodynamic description in the river system.

A lumped approach was applied for the groundwater, while a detailed and distributed approach was applied for the surface water, both handled by MIKE SHE, while MIKE 11 was applied for the river system. The lumped approach (linear reservoir) for the saturated zone calculated the fraction of the rainfall that entered the river system and the ratio between overland-, inter- and base flow. Consequently the hydrological model was not able to calculate actual groundwater elevations and groundwater flow paths, but only the amount of water entering the river system.

MIKE SHE is a comprehensive mathematical modelling system that covers the entire land-based hydrological cycle. It is a finite difference model solving a system of equations describing the major flow and related processes in the hydrological system. The linear reservoir module for the saturated zone in MIKE SHE was developed to provide an alternative to the physically based, fully distributed model approach. The saturated zone is described using a lumped approach where the model area is divided into a number of sub-catchments. For each sub-catchment the flow contribution out of the catchment is calculated using a linear reservoir approach. In the linear reservoir method, the entire catchment is subdivided into a number of sub-catchment and within each subcatchment the saturated zone is represented by a series of interdependent, shallow interflow reservoirs, plus a number of separate, deep groundwater reservoirs that contribute to stream baseflow. If a river is present, water will be routed through the linear reservoirs as interflow and baseflow and subsequently added as lateral flow to the river. Interflow will be added as lateral flow to river links located in the lowest interflow storage in each catchment. Similarly, baseflow is added to river links located within the baseflow storage area.

The MIKE 11 hydrodynamic module uses an implicit, finite difference scheme for the computation of unsteady flows in rivers and estuaries. The module can describe sub-critical as well as supercritical flow conditions through a numerical scheme, which adapts according to the local flow conditions.

The coupling between MIKE 11 and MIKE SHE is made via river links, i.e. segments between two adjacent grid points. The entire river system will always be included in the hydraulic model, but MIKE SHE will only exchange water with the user-specified coupling reaches. When using the linear reservoir approach the interflow and baseflow is calculated and distributed evenly over the 
river links inside the sub-catchment. For the overland flow the flow is routed directly to the nearest river link as the overland solution is a grid based solution. A similar application of coupled MIKE 11 and MIKE SHE models is given by Thompson et al. [6].

The calibration of the current model has been done with very few observation data, and the lumped approach for the groundwater zone only enables a comparison of observed and simulated values for the river system. This allowed for a calibration of the total inflow to the river system, and a verification of the fractioning of flow into fast runoff (overland and interflow) and slow runoff (baseflow). The calibration focused on the flood event in August 2001, and the parameters were calibrated against this event

During the 2001 flood the observation station in Tangrah was destroyed and no actual observation data for discharge or water level exist. Based on the observed depth of the flood and the river characteristics, assumed values for the discharge were calculated. These assumed values are used for the calibration of the discharge values, though as the values are assumed, and not actually observed, the calibration will focus on getting a reasonable correlation with the data, but at the same time maintain some realistic values for the time constants. The maximum discharge at the Tangrah station is assumed to be $1650 \mathrm{~m}^{3} / \mathrm{s}$ at $6.00 \mathrm{AM}$ at the 11th of August.

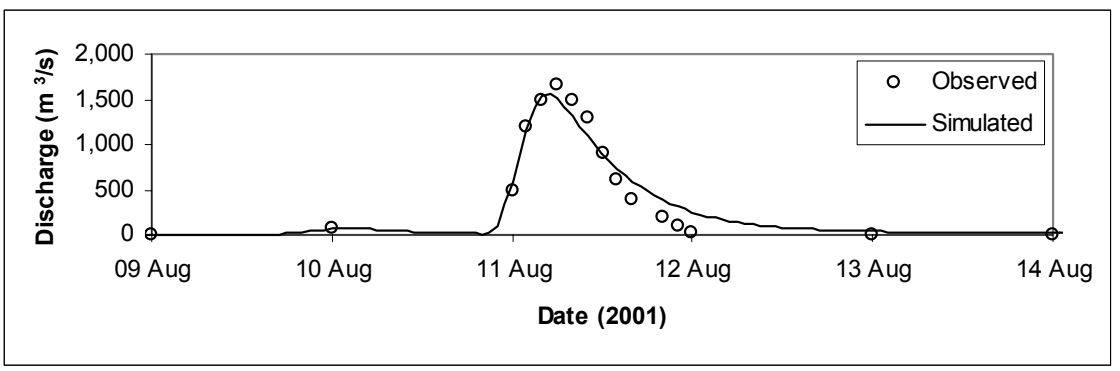

Figure 2: Observed/assumed and simulated 2001 flood.

The model has been calibrated to the best fit using the hourly rainfall distribution and the model is able to produce a reasonable fit with the observed/assumed data, see fig. 2. The simulated peak values in Madarsoo River shows $950 \mathrm{~m}^{3} / \mathrm{s}$ at Dasht, $1559 \mathrm{~m}^{3} / \mathrm{s}$ at Tangrah and $2485 \mathrm{~m}^{3} / \mathrm{s}$ at Golestan Dam, while the travel time from Dasht station to Golestan Dam is around 5 hours. When looking at the fractioning of the run-off at the downstream end, Golestan Dam, the simulation shows that less than $1 \%$ of the flood water originates from baseflow, and that the rest is interflow and overland flow. Using the lumped linear reservoir approach the overland flow and interflow both represents the fast run-off and compared to physical observations it is not possible to separate these two components using the current modelling approach. 


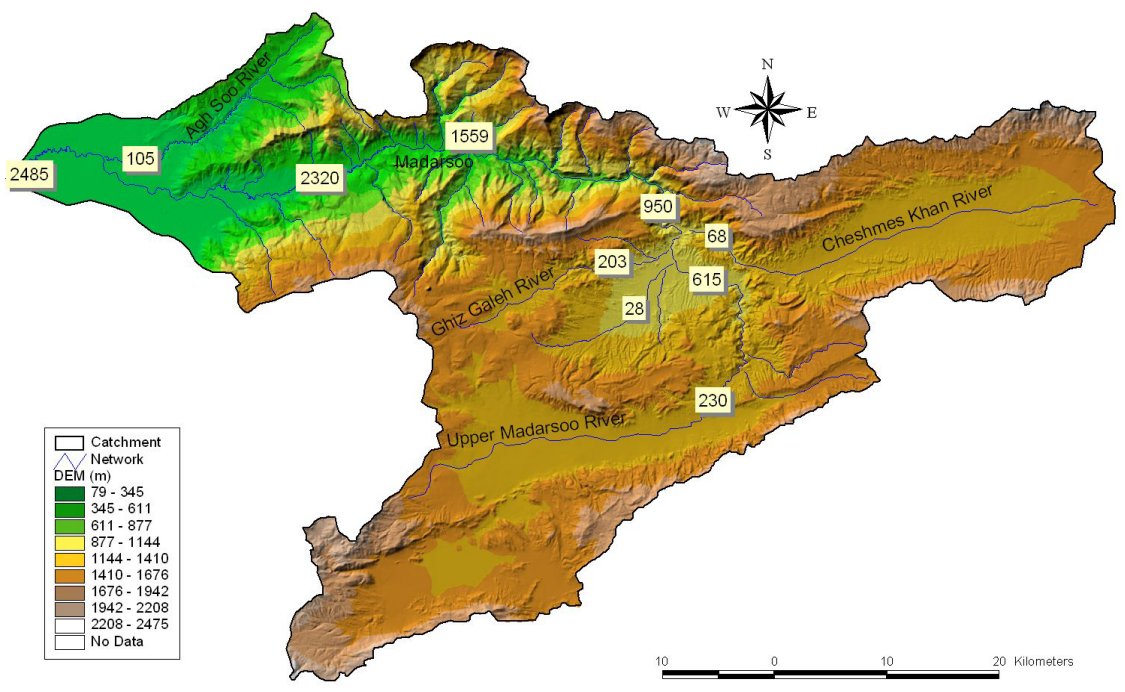

Figure 3: $\quad$ Simulated peak flood values $\left(\mathrm{m}^{3} / \mathrm{s}\right)$ during 2001.

Fig. 3 shows the peak values throughout the river network. It can be seen that the upper plains contribute significantly to the total peak flow. This also indicates that these areas are of great importance if any flood protection measures should be installed.

\section{Hydraulic modelling}

A hydraulic model was constructed to cover the $76 \mathrm{~km}$ reach from Dasht village at the upstream entrance to the narrow Golestan Forest down to the Golestan Dam. The model was constructed with only the Madarsoo River included, while all tributaries were translated into point sources in the network.

Two MIKE 11 models were constructed, an overall hydraulic model (553 cross-sections) for the general flood mapping and a local morphological model (205 of the 553 cross-sections) in the debris prone area. Fig. 4 shows the local MIKE 11 model, while the extent was also indicated in fig. 1.

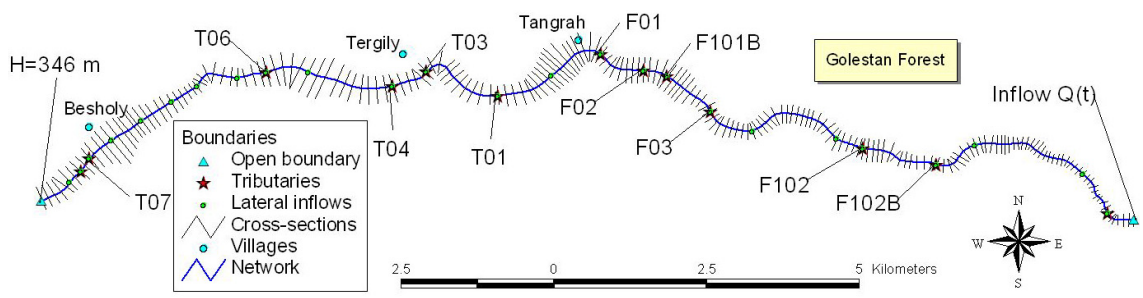

Figure 4: MIKE 11 network, cross-sections and boundary conditions. 
The lateral flows from the hydrological model were translated into point sources in the hydraulic model. The hydraulic model is hence stand-alone compared to the hydrological model where MIKE 11 and MIKE SHE are coupled.

A DEM was provided based on topographic maps and land survey, while river survey cross-sections were provided at an interval of about $100 \mathrm{~m}$. Unfortunately it turned out that the cross-section elevations matched poorly with the DEM, which is not an unusual problem. Therefore the survey cross-sections were omitted and the model based on cross-sections (river and full floodplain) extracted from the DEM. The representation of the river in the cross-sections was obviously not good, but as the 2001 flood in the Madarsoo had very high discharges compared to the capacity of the river channel, most of the floodwaters were flowing in the floodplain. Consequently the accuracy of the actual crosssections is not as important for the purpose of flood modelling.

The river network was digitized from the DEM to ensure consistency in the model. The river was simply located from the contours, and is hence more representative of the floods than of the river flow, as the network represents the flood flow. Therefore the digitized network was about $15 \mathrm{~km}$ shorter than the network according to the river survey, but this is very reasonable, as the floodwaters will travel a shorter distance.

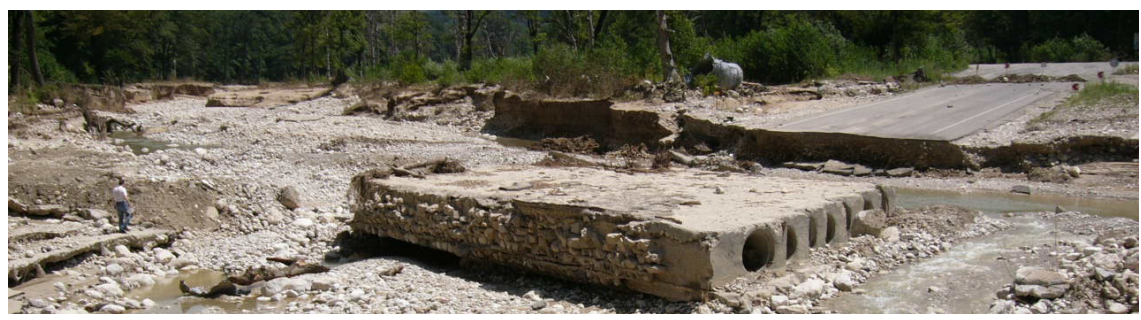

Figure 5: Destroyed bridge in Golestan Forest after the 2005 flood.

19 bridges cross the Madarsoo in the hydraulic model reach. The geometries for the bridges were obtained from difference sources, and the bridges were included by using culverts and weirs (energy equation) for representing the bridge openings and decks. The bridges in Golestan Forest are temporary bridges constructed with culverts ( $1 \mathrm{~m}$ diameter) in a fairly low profile, see fig. 5 , and the floods cause considerable damage to these bridges. Hence, one could argue that bridges that are destroyed during a flood should not be included in the flood mapping calculations; here it was chosen to include them to be more conservative (more flooding due to backwater).

There are water level gauges in the area, but they all fail during the floods, so no water level data was available. Some flood markers were obtained in the project, but these were not particularly applicable. Therefore the model calibration had to be based on engineering judgment, and we used experience to set the Manning $\mathrm{n}$ value in the floodplain and river represented by the crosssections to $\mathrm{n}=0.15 \mathrm{~s} / \mathrm{m}^{1 / 3}$. 


\section{Debris flow}

There are many uncertain elements in the estimation of debris flow volumes, so some engineering judgement was applied in the process. The methodology was fairly straightforward, and it was to estimate the debris volumes from empirical methods and add these volumes as sediment sources in a morphological model in which the grain sizes were estimated from sediment samples taken in the area.

Tributaries with any history of debris flow were classified as "debris prone". The debris prone tributaries were located in a $10 \mathrm{~km}$ reach with steep side slopes and the highest rainfall intensity in the whole river basin. Worst case was considered for hazard mapping, i.e. all tributaries generate debris flow during the considered event. Though this may sound like a lot, the debris events are in fact not very dependent due to the steep slope of the Madarsoo, i.e. debris flow in a tributary has mostly a local effect, and therefore it is reasonable to treat all the debris events in one single calculation.

The theoretical background for debris flow is given by Takahashi [5], and also provides empirical formulas based on experiments. For field applications these formulas dramatically overestimate the debris yield, so a literature study was initiated for finding a reference with a practically applicable debris yield formula.

The debris yield was calculated with a method from USACE, Los Angeles District [7], which gives the debris yield by the empirical expression based on field data from California:

$$
D y=1.66^{F F} Q^{0.85} R R^{0.53} A^{0.04}
$$

where Dy is debris yield $\left(\mathrm{yd}^{3} / \mathrm{mi}^{2}\right)$, Q unit peak runoff $\left(\mathrm{ft}^{3} / \mathrm{s} / \mathrm{mi}^{2}\right)$, RR relief ratio ( $\mathrm{ft} / \mathrm{mi}$ ), A drainage area (acres) and FF a fire factor ranging from 3-6. It is noted that the Los Angeles District Method is strictly only fully valid for California. However, there were no alternatives for the present application, and the Los Angeles District Method should at least give approximate values for the debris yield. The debris yield varied with tributary and flood event, ranging from 5,000$100,000 \mathrm{~m}^{3}$ of debris during one flashflood. As can be seen from the formula, the debris yield is only weakly dependent on the flood event, as the peak discharge is given with an exponent of 0.85 , while the rest of the dependency is topography. The Fire Factor was set to its low value $(\mathrm{FF}=3)$ for the present application, as fires are not important for Madarsoo, but it can be seen from the Los Angeles District formula that fire can dramatically increase the debris yield in a flood following the fire, which is important in California.

To model the formation and break down of deposit deposits, it was necessary to translate the debris yield into time-series of debris flow rate $\left(\mathrm{m}^{3} / \mathrm{s}\right)$. A reasonable assumption is to make the debris flow rate a function of the water discharge from each tributary. However, it turned out that the debris in all cases arrive prior to the bulk of floodwater delayed from further upstream, so the distribution in time of the debris yield is less important. 
The grid spacing in MIKE 11 has to be fairly small (10 m was found to be adequate) to resolve the debris deposit development. It is therefore necessary to make assumptions about the longitudinal distribution of debris. Numerically it is very difficult to simulate the morphological development of a spike in the topography, and physically it does not make sense that the debris should form in a single grid point. Therefore the debris was deposited over 5 grid points $(50 \mathrm{~m})$, estimated by using reasonable values for the longitudinal slope of such deposits.

The debris point sources were added to a MIKE 11 morphological model with a grain size of $54 \mathrm{~mm}$ (JWRC [4]) and Engelund and Hansen [2] sediment transport formula where the sediment transport was reduced relative to the formula value because most of the friction is form friction on the floodplain.

\section{Flood mapping}

Flood maps were generated in GIS by combining the simulated water levels and network with a DEM. A TIN (Triangulated Irregular Network) was created from the simulated water level for each chainage assigned along the corresponding cross-section line. The water surface raster was generated from this TIN, from which the DEM was then subtracted, resulting in a raster with the flood depth.

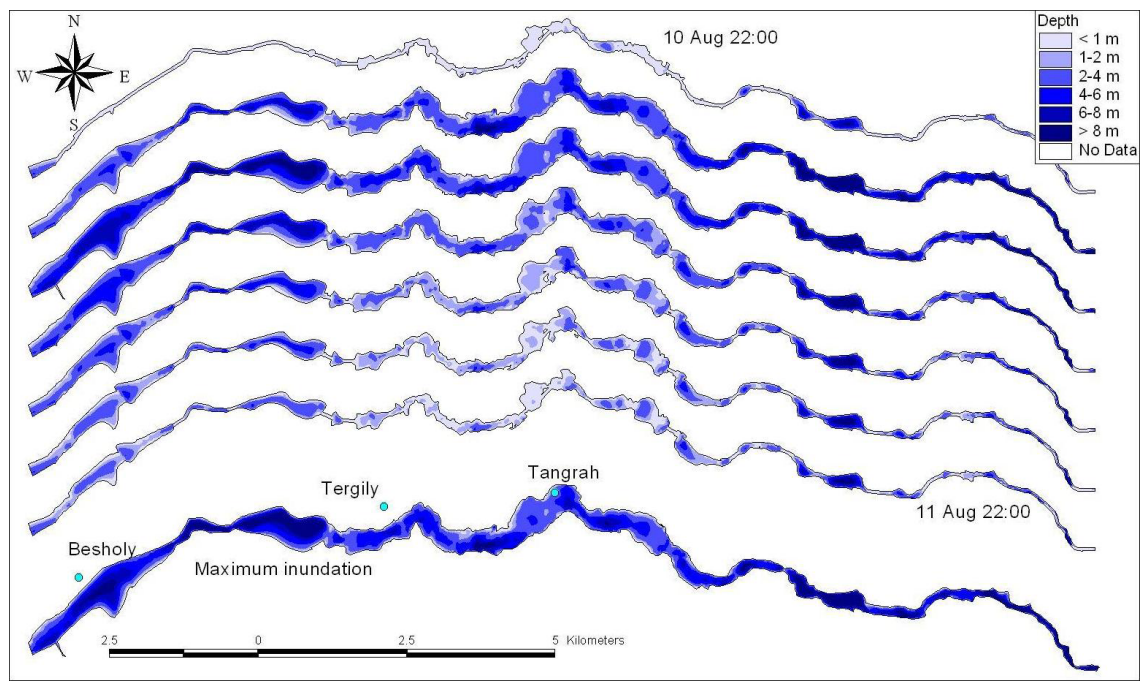

Figure 6: $\quad$ Simulated flood development during 24 hours (4-hourly).

Flood maps for the local model are shown in fig. 6, while difference maps (flood depth with debris flow minus flood depth without debris flow) are shown in fig. 7. It can be seen from the difference map that the debris flow increases the water depth at the debris location, which is then backed up through the river up to $1 \mathrm{~km}$. The impact on the flood extent (also shown in fig. 7 as the "Now wet" areas) is modest due to the steep side slopes of the Madarsoo. From the flood extent it was found that the flooded area would increase by about $2.8 \%$ in this 
area due to the debris flow. In disaster management terms the added depth is of less importance because people relate easier to a flood extent than to a flood depth, though this does not mean that the added depth is not a danger. Animations of the 100 year flood can be found at the JICA Madarsoo project website [3].

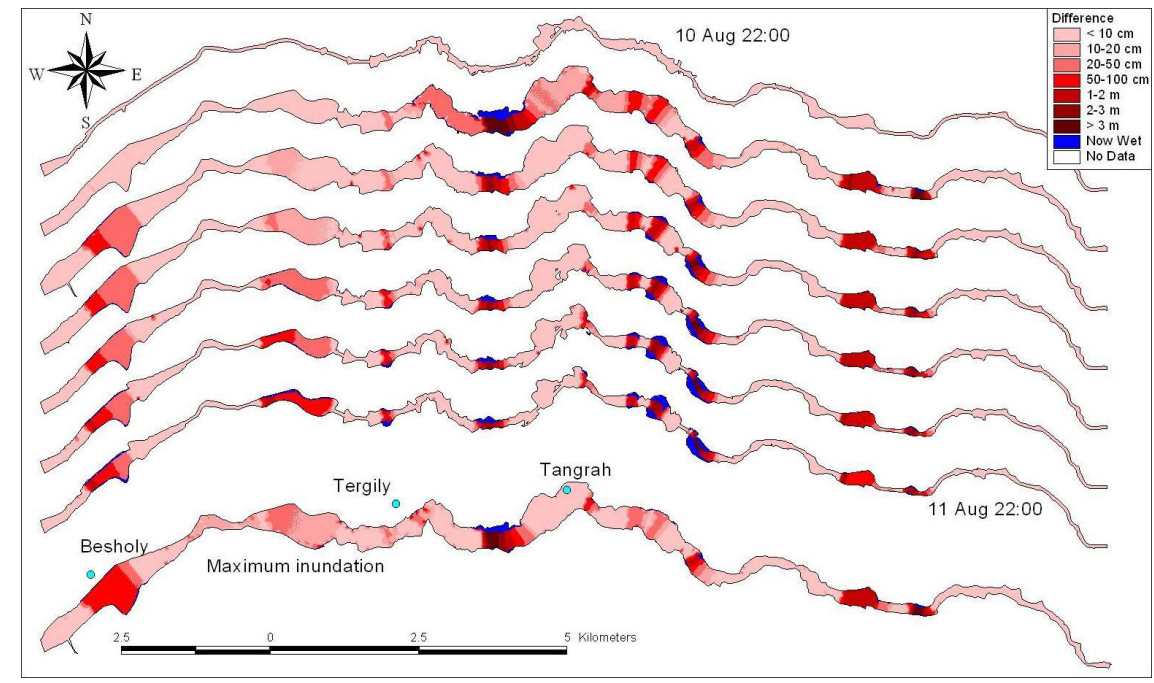

Figure 7: $\quad$ Simulated difference by debris during 24 hours (4-hourly).

The formation and subsequent degradation of the debris deposits leads to a surging effect in which water is stored behind the debris on the rising limb of the hydrograph and released as the deposit is degraded, which increases the peak discharge. This effect was quantified with the model by extracting the simulated discharge with and without debris flow included, results shown in fig. 8.

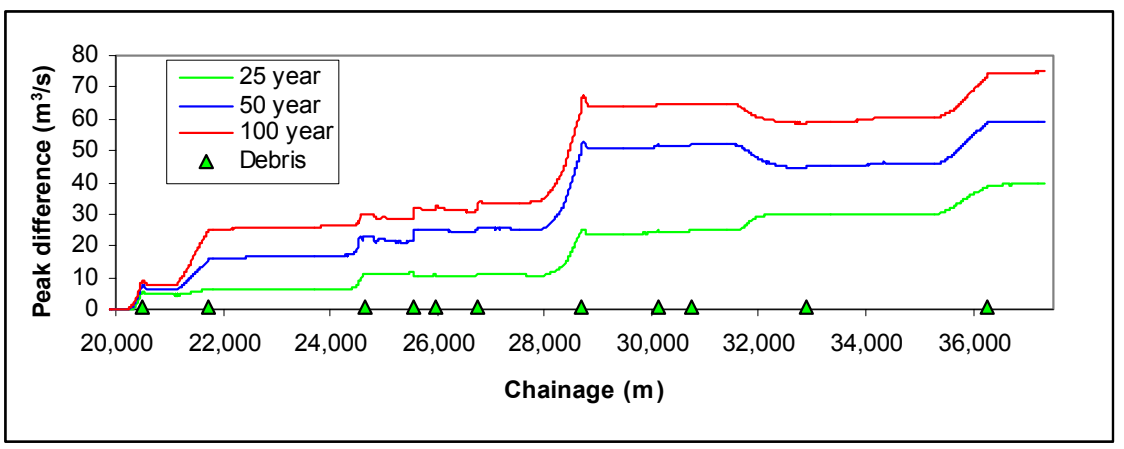

Figure 8: $\quad$ Simulated difference in peak discharge. 


\section{Conclusions}

The present paper describes flood mapping and debris flow impact assessment in Madarsoo River, Iran.

The overall water flow in the basin was determined with a hydrological model handling the rainfall runoff and overland flow coupled with a hydraulic model accounting for the river flow.

A stand-alone hydraulic model was then applied with boundary conditions and lateral inflows from the hydrological model. This model was used for flood mapping and for determining boundary conditions for a local morphological model with debris flow included.

Debris flow was handled by calculating the debris yield for tributaries with a history of debris flow (classified as debris prone) from an empirical formula. It was argued that the debris would arrive before the main floodwaters from further upstream by assuming some correlation with the local tributary discharge, and hence the distribution in time of the debris flow rate is irrelevant. The debris yields were then translated into sediment source time-series and applied in a morphological calculation. Simulations were performed for the 25, 50 and 100 year events with and without debris flow included.

Flood maps were produced by combining the hydraulic models with the DEM. The dynamic 100 year flood and the impact of debris flow on this flood were presented, while the storing on the rising limb and release of floodwater on the flood peak from behind the debris deposits causes a surging effect that increases the peak discharge. The flood maps were used in the formulation of a master plan for the area.

\section{References}

[1] El-Nasr, A. A., Arnold, J. G., Feyen, J., Berlamont, J., Modelling the hydrology of a catchment using a distributed and a semi-distributed model, Hydrological processes Volume 19, Issue $3,28^{\mathrm{TH}}$ of February 2005, Pages 573-587.

[2] Engelund, F. \& Hansen, E., A monograph on sediment transport in alluvial streams, Teknisk Forlag, Copenhagen, 1967.

[3] JICA Madarsoo project website, www.jica-madarsoo-study.com.

[4] JWRC, Report of geo-technical study and stability of material, urgent plan for prevention of damage caused by flood in Gorgan River Basin, in Farsi (data in English), Jahad Water and Watershed Management Research Company, 2004.

[5] Takahashi, T., Debris Flow, IAHR Monograph, 1991.

[6] Thompson, J. R., Sørensen, H. R., Gavin, H. and Refsgaard, A., Application of the coupled MIKE SHE/MIKE 11 modelling system to a lowland wet grassland in southeast England, Journal of Hydrology, Volume 293, Issues 1-4, June 2004, Pages 151-179.

[7] US Army Corps of Engineers, Los Angeles District, Los Angeles District Method for Prediction of Debris Yield, 2000. 